\title{
Zero-turn-off thyristor zero voltage block media recovery analysis of influencing factors
}

\author{
FANG Wei ${ }^{1, a^{*}}$, XU Guo-shun ${ }^{1, b}$, ZHUANG Jin-wu ${ }^{1, c}$ \\ ${ }^{1}$ College of Electrical Engineering, Naval University of Engineering, \\ Wuhan 430033, Hubei Province, China \\ a2324720717@qq.com, b245693405@qq.com, ${ }^{c} 13871161550 @ 139 . c o m$
}

\section{Keywords: Turn off thyristor recovery, Size of the through-flow, Current flow time}

\begin{abstract}
For the analysis of transient zero through the thyristor turn-off characteristics of recovery factors, the researchers are by changing the polarity of the supply voltage of the anode current commutation always realize thyristor is turned off, but will be under a lot of anti-off thyristor during recovery forward voltage, and this paper was forced commutation thyristor zero crossing, after the zero-crossing through the freewheeling diode voltage across the thyristor is zero, so the previous studies are not suitable for the object of this article. This paper presents the experimental circuit thyristor forced through zero-zero-voltage shutdown recovery by the experimental system to study the effects of the thyristor transient recovery time of two important factors, and in respect of factors (the size of the through-flow, flow time) thyristor recovery time characteristics of the particular what impact do a detailed analysis and the results showed that: the thyristor through-flow growth and an increase in the magnitude of flow-through time will adversely affect their recovery time.
\end{abstract}

\section{Introduction}

Thyristors are widely used in high-voltage, high-power electronic systems, which turn-off thyristor recovery problem has attracted more and more attention. In this paper, in order to prevent a vacuum contact breakdown delay, reduce energy arc vacuum interrupter when it is open, we use the natural method of parallel thyristor commutation in advance to reduce arcing time, so as to reduce arc energy effect [1]. However, in principle, the administration of a certain turn-off thyristor recovery time, after a certain period of time will produce the same forward voltage at both ends of the thyristor at this time if the recovery time is not enough [2], will cause the thyristor is turned on again, thereby turning off failed. So effective recovery factors affect thyristor is necessary.

Thyristor cut off has a variety of ways, both former researchers by changing the polarity of the supply voltage of the anode current commutation always realize thyristor is turned off, but will be under a lot of reverse voltage during turn-off thyristor recovery [3], this will thyristor recovery to a certain extent, but this paper is forced commutation thyristor zero-crossing, the thyristor is smaller than the current flowing through the thyristor holding current, final GTO. Thyristor in this process after the zero crossing, parallel diode clamping action began to lose, and off the branch formed freewheeling, free-wheeling diode through both ends of the thyristor recovery voltage is zero, the previous studies are not suitable for this article object.

This paper presents the experimental circuit through the thyristor forced shutdown zero voltage recovery, changing the size of the thyristor current conduction through-flow time, and recovery time by changing the capacitance of the charging voltage thyristors through experimental system to study the effects of the thyristor transient recovery time two important factors ${ }^{[4]}$, and in respect of factors (the size of the through-flow, flow time) specifically what the impact on the characteristics of the thyristor recovery time to do a detailed analysis, The results show that: the thyristor through-flow growth and an increase in the magnitude of flow-through time will adversely affect their recovery time $^{[5]}$. 


\section{Effect Transistor off Recovery Time Factor and Experimental Results}

Fig. 1 below shows the schematic recovery thyristor shutdown line parameter $\mathrm{C} 1=90 \mathrm{mF}$ main circuit resistance $0.31 \Omega$, turn off the circuit $\mathrm{C}=100 \mathrm{uF}$ charge Uco inductance $\mathrm{L} 1=5 \mathrm{uH}$ let the main circuit is turned on, so that thyristor T1 through-flow for some time, send off signal so that thyristor $\mathrm{T} 2$ is turned on, thereby forcing commutation branch $\mathrm{T} 1$ after commutation, turn off the energy from the capacitor on the freewheeling diode $\mathrm{D}$, so that the $\mathrm{T} 1$ zero voltage recovery. Methods: By changing the time-triggered thyristor T2 signal to change the TI flow-through time; by varying the main circuit power supply voltage to change the size of the through-flow; ultimately by changing capacitor charging voltage Uco and off to change the thyristor branch commutation time recovery time to give control thyristor zero voltage.

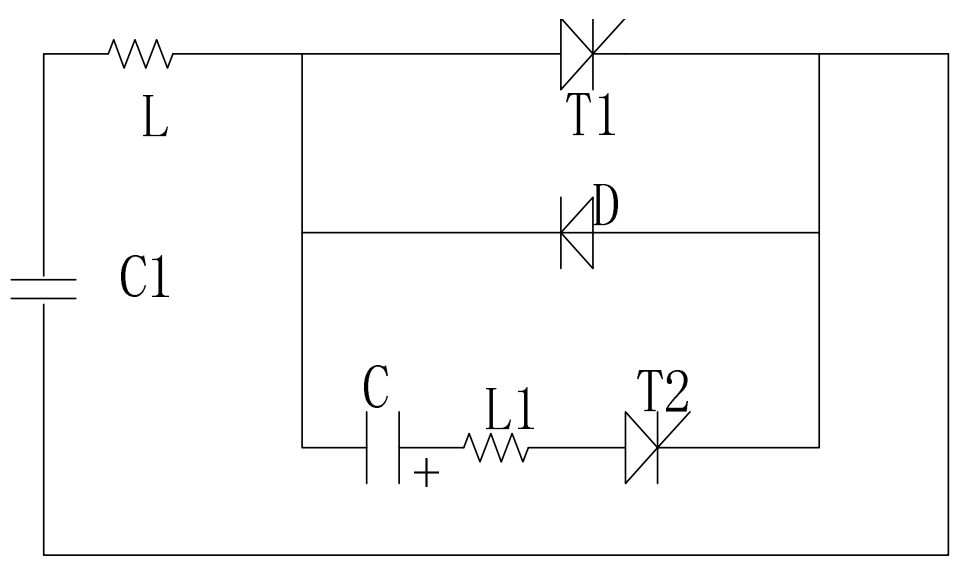

Fig. 1 Off thyristor recovery experiment Schematic.

Off thyristor follows a different experimental conditions under the current circumstances and off again conducting experimental waveforms:

Fig. 2 parameters: Power supply voltage $900 \mathrm{~V}$ Uc charging $1100 \mathrm{~V}$ through-flow $6 \mathrm{~ms}$ 2500Asuccess off recovery time 46us

Fig. 3 parameters: Power supply voltage $900 \mathrm{~V}$ Uc charge $1010 \mathrm{~V}$ through-flow $6 \mathrm{~ms} 2500 \mathrm{~A}$ is turned off and the recovery time is 43us Recovery time for the thyristor current falls to zero from time to time pressure at both ends of the thyristor. Fig. 2 is a turn-off thyristor recovery is successful, Fig. 3 is not completely off the thyristor recovery failure.

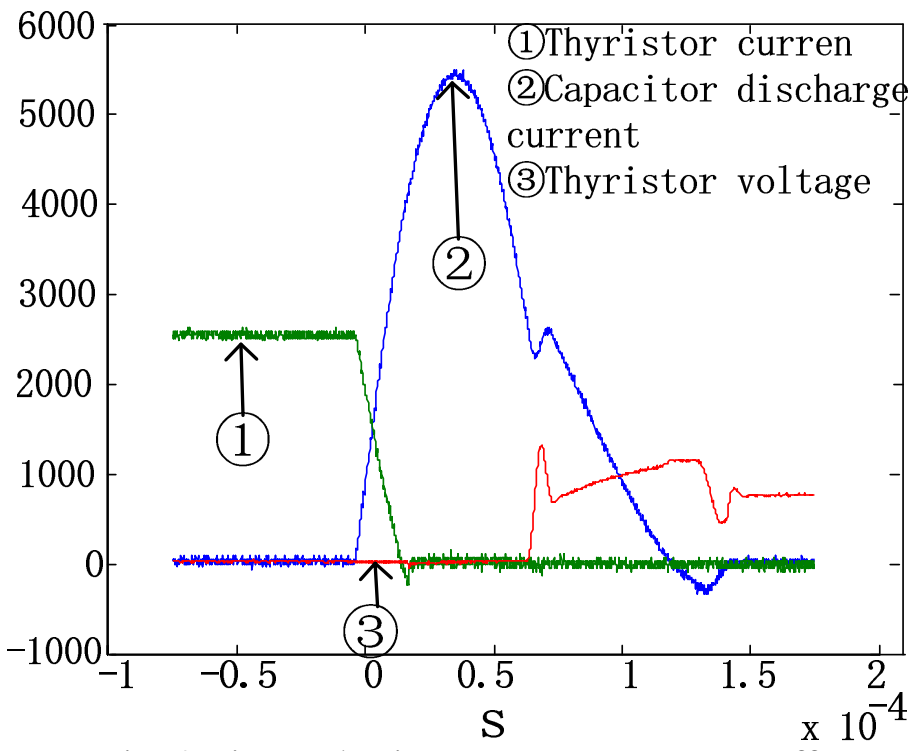

Fig. 2 Figure thyristor recovery success off. 


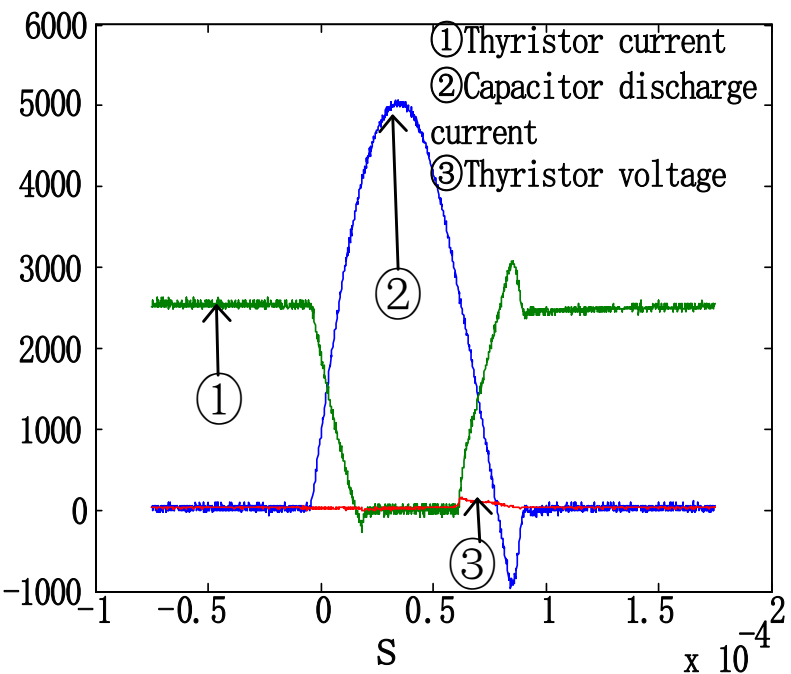

Fig. 3 is not completely off the thyristor recovery failure Figure.

As shown in FIG experimental waveforms: thyristor flow-through period of time, t1 time begin to reverse the off current, $\mathrm{t} 2$ time thyristor zero flow, this time due to the loss of the diode clamping action is turned on, the thyristor blocking voltage recovery began to zero, $\mathrm{t} 2 \sim \mathrm{t} 3$ to give the recovery time of the thyristor, The first figure is zero voltage is greater than the recovery time from the time a final successful pressure, the second picture time is less than zero voltage thyristor recovery time, recovery is not complete, the final thyristor again turned on. Thus we can see that the critical value of the thyristor recovery time at a certain state from the experimental waveforms.

The overall results: Table 1 below.

Table 1. The results of in case of different parameters.

\begin{tabular}{c|ccc}
\hline I & $2 \mathrm{~ms}$ & $6 \mathrm{~ms}$ & $10 \mathrm{~ms}$ \\
\hline $1000 \mathrm{~A}$ & $12 \sim 18 \mathrm{us}$ & $15 \sim 20 \mathrm{us}$ & $18 \sim 22 \mathrm{us}$ \\
$2500 \mathrm{~A}$ & $39 \sim 42 \mathrm{us}$ & $43 \sim 46 \mathrm{us}$ & $>66 \mathrm{us}$ \\
\hline
\end{tabular}

The relationship between the recovery time of thyristor and the flow time and the size of the flow is shown in Fig. 4.

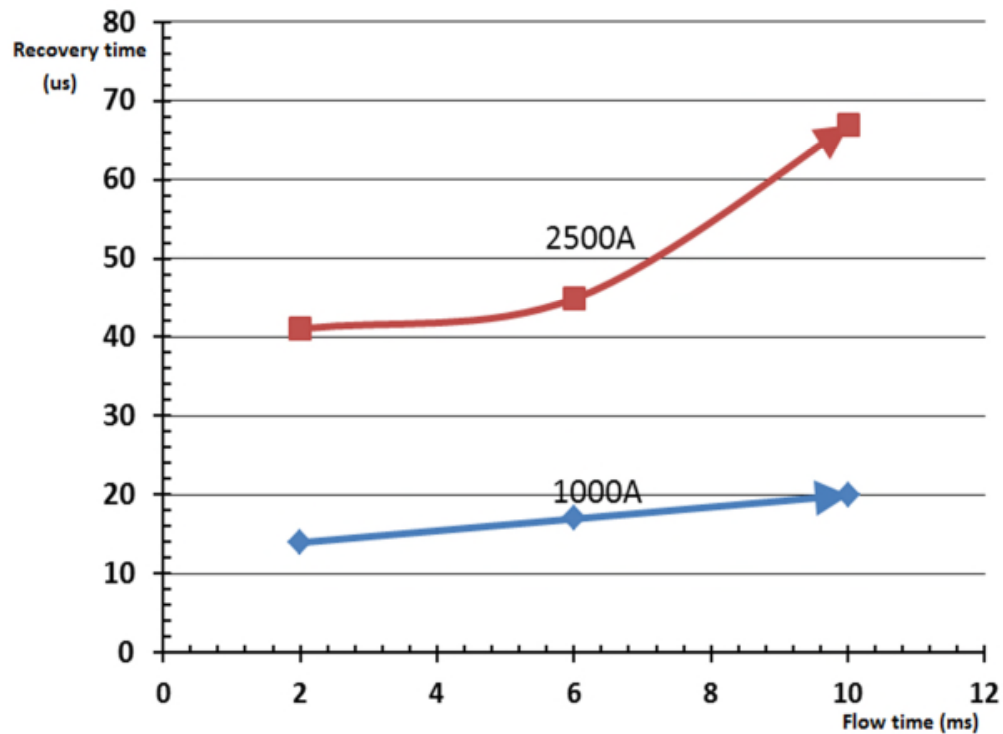

Fig. 4 Relationship between recovery time, current follow time and forward current. 


\section{The Results of the Theoretical Analysis}

According to the results the following results from the theoretical analysis of the correctness of the above.

Transistor PN junction composed of three, when the blocking state, the thyristor junction $\mathrm{J} 1$ and $\mathrm{J} 3$ is a slight positive bias [5], J2 junction is reverse biased withstand almost all the off-state voltage. Due to the reverse junction $\mathrm{J} 2$ limit, the device can only flow through a small leakage current. If the gate with respect to the forward-cathode voltage VG, there will be a gate current Ig and an anode current in the same direction through the junction $\mathrm{J} 3$, so the current through the junction $\mathrm{J} 3$ will no longer reverse biased junction $\mathrm{J} 2$ restrictions, as long as the change plus in the $\mathrm{J} 3$ junction voltage [6], it can control the size of the current junction J3. When Ig increases, the current through the junction $\mathrm{J} 3$ is also with the increase, thus causing N2 P2 region to region to inject many electrons recombine with holes a part, forming a part of the gate current, the other part of the electron in the $\mathrm{P} 2$ region by diffusion reach $\mathrm{J} 2$ junction is collected $\mathrm{N} 1$ zone, thus causing increased electron current through the junction $\mathrm{J} 2$ [7]. Electrons are collected N1 potential drop zone makes the region so that more forward-biased junction $\mathrm{J} 1$, a hole injection current increases, the current through the IA P1N1P2N2 structure also increases to form a positive feedback, eventually thyristor. Opening characteristic thyristor residual carrier concentration process flow established over time through the base area.

Conducting thyristor when forward current is cut off, and can not be shut off immediately, then as now with a positive voltage, it will turn back on. Thyristor turn-off characteristics through the carrier concentration determined over time disappear, the remaining carriers must be reduced to make the accumulated charge less than the critical charge stored from the time off until the gate forward current recovery process control required called off-time, Indicated by $t_{\text {off }}$. Herein thyristor is turned off $\left(\mathrm{I}_{\mathrm{A}}=0\right)$, no remaining carriers to flow out, they can only disappear by recombination, the thyristor turns off due to the current base just after the zero PN there are a large number of carriers [8], in order to restored to its original blocking state of concentration, so the rest of the carriers need to continue to spread, the hole and electron recombination, and ultimately achieve our desired critical storage charge. Increasing the flow-through time in this study ie the thyristor junction temperature increases, explained the physical meaning of this process: the junction temperature increase will increase the base carrier lifetime, resulting in a longer recovery time. Increasing the through-flow magnitude which will increase the amount of charge stored in the base area, resulting in a longer recovery time [9]. We found that the longer flow through the thyristor, thyristor junction temperature greater the following (2) to calculate the junction temperature: instantaneous power thyristor is followed (1):

$$
\begin{aligned}
& p(t)=i(t) * v(t) \\
& T_{j}=T_{0}+p(t) * \frac{d Z_{j}(t)}{d t}
\end{aligned}
$$

$T_{0}$ is Room temperature; $Z_{j}(t)$ is thyristor transient thermal resistance in combination with the valve heat sink; In fact, most of the excess charge are located $n 1$ base in the region of the turn-off characteristics of the thyristor has a decisive role [10]. Use charge control equation is followed (3), the charge storage effect of the base region can be described as follows:

$$
i=\frac{d Q}{d t}+\frac{Q}{\tau}
$$

$Q$ is Base excess charge; $i$ Base excess carrier lifetime; i is flowing into the $n 1$ base of the current. Suppose thyristor anode and cathode emission efficiency is 1; and off the course, $\tau$ remain unchanged [11-14], $i$ with the anode current (di / dt) at a rate of decrease in the anodic 
current $i$ zero excess charge of base is followed (4):

$$
Q_{B}=Q_{F} *\left(1-e^{t_{0} / \tau}\right) * \frac{\tau}{t_{0}}
$$

Formula $Q_{B}$ as the anode current zero time charge amount of excess base; $Q_{F}$ when the current begins to decrease the amount of excess charge base area; ${ }^{\alpha_{n n}}$ is part of the device n1p2n2 common base current gain; $t_{0}$ as the anode current zero moments.

By the above formula, we can see a qualitative increase in flow-through time of the thyristor junction temperature increases [15-16], so that the base region of carriers harder compound will cause an increase in the effective carrier lifetime composite boundary effects, recovery time of the final shutdown increases. Further increasing the flow through the thyristor amplitude increases the carrier injection region of the base, so as to increase the recovery time of the thyristor [17].

\section{Conclusion}

In this paper, high power thyristor turn-off recovery process by theoretical analysis and experimental results show found herein conditions off thyristor recovery time and through-flow time, flow size.

(1) The longer the flow-through time causes junction temperature greater the more the charge to recover the lead to longer recovery time of the thyristors.

(2) The greater the magnitude of the charge stored through-flow injection of more thyristor causing longer recovery time.

\section{References}

[1] D. S. James, R. Elyse. A scalable SCR compact model for ESD circuit simulation. IEEE CFP08RPS-CDR 46 Annual International Reliability Physics Symposium, Phoenix, 2008 1-6.

[2] L. F. Lou, J. J. Liou. An improved compact model of silicon-controlled rectifier (SCR) for electrostatic discharge (ESD) applications. IEEE Trans. Electr. Dev. 55(10) (2008) 45-59.

[3] D. W. William, F. W. William. Thermal modeling and experimentation to determine maximumpower capability of SCR's and Thyristors. IEEE Trans. Power Electr. 1(14) (1999) 20-36.

[4] D. J. Yang, Z. H. Yao, C. C. Zhu, Principle and technology of new power electronic device igct (integrated gated commutated thyristor). Power Electr. 45(16) (1999) 555-557.

[5] Y. L. Lan, G. F. Tang, Y. H. Yin, et al. Study on transient of reverse recovery of series thyristors. Power Syst. Tech. 30(16) (2006) 15-19.

[6] J. Chester. A new technique for deriving self-consistent electrical and thermal models of thyristors during surge loops and experimental data//IEE 1977 Conference Publication. London IEE, (1997), pp. 154-158.

[7] G. N. Revankar, P. K. Srivastava. Turnoff model of an SCR. IEEE Trans. Ind. Elec. Contr. Instr, 1975, IECI-22507-510.

[8] C. W. Lee, S. B. Park. An optimum parameter determination for the SCR turnoff model. IEEE International Symposium on Circuits and Systems, Paris, 1987, 51018-1021.

[9] W. L. Chang, B. P. Song. Design of a thyristor snubber circuit by considering the reverse recovery process. IEEE Trans. Power Electr. 3(4) (1988) 440-446.

[10] Z. Y. Zhao, Y. C. Qiu, Y. M. Yu, et al. Analysis of voltage distribution in HVDC converter valve by macro-model of thyristor. Power Syst. Tech. 27(9) (2003) 33-36. 
[11] Task Force 01 of Working Group 14. 01. Voltage and current stresseson HVDC valves. Electra, 125(7) (1989) 58-86.

[12] H. Gibson, J. P. Ballad, J. K. Chester. Characterisation, evaluation and modeling of thyristors for HVDC converter valves. Fourth International Conference on AC and DC Power Transmission, London, 1985. 48-76.

[13] H. Guo, J. L. Wen, G. F. Tang, et al. Analysis of the turn-off Voltage Stress on HVDC Thyristor Valve. Proceedings of the CSEE, 30(12) (2009) 1-6.

[14] D. Li, Q. M. Li, W. D. Liu, et al. Investigation of a double current-transferring typeshort circuit current limiter. Trans. China Electrotech. Soc. 19(3) (2004) 21-24.

[15] C. Wang, J. W. Zhuang, X. F. Zhang, et al. Principle and test of a novel fault current limiter based on IGBT for DC power system. Trans. China Electrotech. Soc. 21(9) (2006) 57-61.

[16] X. S. Zhou, L. R. Xiang, Y. J. Ma, et al. The development and application of fault current limiting device. Trans. China Electrotech. Soc. 19(11) (2004) 1-7.

[17] Z. J. Wang, J. J. He, X. G. Yin, et al. $10 \mathrm{kV}$ highspeed vacuum switch with electromagnetic repulsionmechanism. Trans. China Electrotech. Soc. 24(11) (2009) 68-75. 